\title{
As novas formas de hegemonia: a construção do consenso da empresa feliz
}

Augusto Cesar Oliveira ${ }^{1}$

O trabalho que pretendo apresentar é uma reflexão a respeito da construção do consentimento dos trabalhadores no capitalismo atual que leva em conta dois aspectos principais: 1) a maneira pela qual o estágio atual da inovação tecnológica cria exigências e condições para que haja um certo tipo de trabalhador e 2) o "cenário cultural" no qual as técnicas gerenciais surgem e se desenvolvem justamente para realizar praticamente esta tarefa de forjar um certo tipo de trabalhador.

Numa abordagem mais geral, minha pesquisa se insere no debate sobre as recentes transformações no mundo do trabalho e seu objeto privilegiado são algumas técnicas ou práticas gerenciais. As práticas que narro aqui foram observadas por mim numa pesquisa de campo realizada ao longo de alguns meses no biênio 2000/2001 numa empresa sediada na região metropolitana do Rio de Janeiro. A referida empresa foi criada em 1994 por iniciativa de algumas grandes empresas nacionais (no sistema de sociedade anônima) para ser concessionária de um serviço público recém privatizado. Com o decorrer da pesquisa ficou claro que essa empresa era tida (por estes grandes acionistas) como um importante elemento de marketing para que o processo de concessão fosse avaliado positivamente pelos governos e população e se expandisse no futuro. Creio que desta condição específica deriva o fato de que a referida empresa seja um caso exemplar da implantação do que chamei doutrina da qualidade de

$-\cdots$

1 Doutor e Mestre em Sociologia pelo IUPERJ. Atualmente é professor substituto no Dep. de Sociologia do IFCS/ UFRJ. Contato: aoliveira@iuperj.br.

cadernos cemarx, $n^{0} 2-2005 \mid 35$ 
vida do trabalhador (DQVT); isso por que, segundo os próprios informantes que tive na empresa, o fato dela procurar ser uma empresa feliz faria parte de uma estratégia empresarial. Esta nomenclatura, DQVT, se deve ao fato de que esta nova maneira de organização do trabalho concentra fortemente seu discurso em torno da questão do bem estar no local de trabalho. A frase Esta é uma empresa feliz foi vista por mim repetidas vezes nos quadros de avisos de repartições desta empresa e, na minha opinião, ela é um emblema do objeto que tento aqui descrever.

Como dizia, escolhi abordar esta doutrina avaliando inicialmente sua vinculação a certas modificações impostas pelo modo de produção capitalista: a DQVT não pode ser pensada fora do contexto da chamada Terceira Revolução Tecnológica (TRT), o que significa afirmar que a DQVT não pode ser vista como um doutrina (uma técnica gerencial) deliberadamente inventada e imposta às relações de trabalho. Em contrapartida, a análise da DQVT também não pode ser feita como se ela fosse mero reflexo superestrutural de um fenômeno infraestrutural2 ; além de referente a um universo ideológico próprio (a teoria geral da administração), a DQVT se constitui dentro de um debate social mais geral que lhe conforma.

Talvez não seja demasiado banal iniciarmos afirmando que, como diz Wallerstein, o capitalismo se baseia na mercantilização dos processos sociais ${ }^{3}$. Com isto, o autor se refere ao fato de que, como a produção capitalista depende de insumos provenientes dos processos sociais - por exemplo, a empresa precisa que os seres humanos façam alguma quantidade de sexo para que haja futuros trabalhadores e consumidores, que haja famílias que disponham seus membros como futuros operários, que haja cidades onde indústrias possam se instalar...-, a tendência é que os próprios capitalistas, de maneira mais ou menos orquestrada, interfiram diretamente nestes processos sociais para que eles se ajustem aos seus interesses pelo lucro. "O desenvolvimento histórico do capitalismo envolve o impulso de mercantilizar tudo" ${ }^{4}$. As várias etapas da produção de disciplina social no capitalismo cumprem esta tarefa de mercantilização disponibilizando a população de certa maneira que se coadune com demandas da acumulação capitalista. A DQVT seria

$--\cdot--$

20 que implicaria uma concepção equivocada da instância ideológica baseada numa apreciação mecanicista da problemática imagem infraestrutura/superestrutura.

3 Immanuel Wallerstein, Capitalismo Histórico e Civilização Capitalista, Rio de Janeiro, ed. Contraponto, 2001. 4 Idem, ibidem, p. 15.

36 As novas formas de hegemonia: a construção do consenso da empresa feliz 
uma destas formas de disciplinarização do trabalhador que atuam sobre as necessidades da produção capitalista.

Ainda uma outra perspectiva importante no estudo da DQVT é aquela aberta pela obra do marxista italiano Antônio Gramsci. Através do conceito de hegemonia, Gramsci aumentou enormemente os horizontes da reflexão marxista afirmando que o capitalismo engendra e demanda uma penetração mais profunda no tecido social que aquela que decorre da assim chamada acumulação primitiva ${ }^{5}$ e maior mesmo que a penetração no aparelho estatal das demandas (contraditórias) dos interesses do diversos ramos capitalistas que se encontram em disputa ${ }^{6}$. É sintomático que este autor, num famoso texto sobre esse processo $^{7}$, trate ao mesmo tempo das medidas do famoso empresário Henry Ford em relação aos empregados de sua fábrica, das medidas repressivas do governo estadunidense a "toda" sociedade através da Lei Seca e, finalmente, das campanhas moralizantes movidas por associações civis -sem vinculação direta com o Estado e com a competição econômica- como a YMCA ${ }^{8}$ e o Rotary Club. Cada uma destas medidas tomadas por diferentes personagens em diferentes esferas sociais concorria, de alguma maneira, para a construção de uma disciplina social conforme as necessidades da produção capitalista naquele momento, ou seja, cada uma destas atuações tratava de impor ao cotidiano certos padrões necessários ao processo mercantil da época.

As reflexões de Gramsci, como se sabe, se referem substantivamente ao fordismo, ou seja, a um conjunto de condições tecnológicas, práticas organizacionais, arranjos macro-políticos e configurações socioculturais que surge no início do século

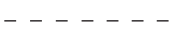

5 Capítulo XXIV de Karl Marx, "A assim chamada acumulação primitiva”, In: 0 Capital,Rio de Janeiro, Ed. Bertrand Brasil, 1994, livro I, vol. II. Entre as mudanças provocadas por este processo teríamos o entesouramento da burguesia através do saque colonial e do endividamento público, a expropriação da população dos seus meios produtivos e a acumulação de fato e de direito destes nas mãos da burguesia, o uso de um trabalho alheio compulsório...

6 “O poder político do Estado moderno nada mais é do que um comitê para administrar os negócios comuns de toda a classe burguesa" (Karl Marx \& Friedrich Engels, Manifesto do Partido Comunista, Petrópolis, Ed. Vozes, 1988, p. 68).

7 Antonio Gramsci, “Americanismo e Fordismo" In: Maquiavel, a política e o Estado Moderno, Rio de Janeiro, Ed. Civ. Brasileira, 1991.

8 Young Male Christian Association, entidade que persiste até nossos dias. No Brasil, chama-se Associação Cristã de Moços.

cadernos cemarx, $n^{0}-2-2005,37$ 
XX, se consolida após a Segunda Guerra Mundial e entra num processo de alteração profunda a partir das décadas de 60/70. Um dos fatores desta alteração deriva da ampla influência das tecnologias de informação -trata-se do contexto da TRT ${ }^{9}$. Dentro da fábrica -e ainda com mais força nas tarefas de escritório- a absorção da informática permite uma extrema rapidez na produção, uma rapidez tal que o próprio ato de produzir a mercadoria se torna amplamente secundário - na verdade, indistinguívelse comparado aos atos que irão decidir o que e como se produzirá assim como aos atos de previsão e avaliação da performance da mercadoria e da empresa no mercado. Nesse contexto, é o tempo que se torna a mercadoria crucial e a agilidade e rapidez nas decisões passam a ser os elementos decisivos na estratégia de cada capitalista individual para "vencer a concorrência"10. O modelo gerencial que acaba se acoplando a esta TRT incorpora, justamente por causa da sofisticação dos instrumentos de controle, as "preocupações comerciais" -ou seja, problemas de concepção, planejamento e controle de execução- durante todo o processo de produção da mercadoria.

A prática acabou demonstrando que, para lidar com esta tecnologia e o cenário competitivo que ela impõe, a organização de trabalho típica do modelo taylorista -delegação de funções simples e atomizadas que só podem ser alteradas mediante determinação dos níveis hierárquicos superiores- deveria ser substituída por uma outra: grupos de trabalho ficam responsáveis por realizar determinadas etapas do trabalho e, ao mesmo tempo, controlar este desempenho otimizando os recursos produtivos e avaliando o cenário da competição empresarial - o que se chamou de autogestão da disciplina do trabalho ${ }^{11}$. Neste cenário, cada participante do grupo exerce uma plêiade de atividades contíguas orientado pela meta abstrata da "otimização organizacional"12 ; neste contexto, o papel da gerência fica sendo o de fomentar uma sensação de insaciedade permanente frente ao desempenho do trabalho. Temos uma boa idéia de que tipo de atitude se está falando analisando a própria linguagem nativa: os gerentes que investigamos dizem que o empregado ${ }^{13}$ deve ter pró-

$-\cdots-\cdots$

9 “(...) a saber, o desenvolvimento da micro-eletrônica, da biotecnologia, da cibernética (...)” (C. Andrade, Reestruturação Capitalista e o mundo do trabalho no pós-crise de 1970, Rio de Janeiro, dissertação de mestrado, IUPERJ, 1999, p.42).

10 Idem, ibidem, p. 43.

11 Idem, ibidem, p. 44.

12 Idem, ibidem, p. 43.

13 Aqueles que entrevistamos se recusam a usar tal nomenclatura: uma empresa não tem empregados, tem colaboradores...

38 As novas formas de hegemonia: a construção do consenso da empresa feliz 
atividade, ou ainda, compromisso com a melhoria constante ${ }^{14}$. Ambos os termos se referem a uma disposição voluntária de cada trabalhador para criar novos ótimos organizacionais enquanto ele desempenha suas tarefas. Para perseguir esta melhoria constante, ele não irá seguir um script formal de atividades pelas quais ele deva ser pago, ele deverá agir da maneira semelhante ao artesão que livremente elabora um detalhe da etapa de tecelagem para que o resultado final seja qualitativamente superior ao que se produz tradicionalmente.

Desta forma, o empregado que deve agir como artesão ${ }^{15}$ (ou, para usar um termo nativo, $O$ colaborador) contribui incessantemente para o próprio aprimoramento produtivo durante o seu trabalho ${ }^{16}$. Essa melhoria constante se torna um fator palpável de produção na medida em que elementos como a performance da empresa no mercado, mudanças notadas e previstas no mercado consumidor... são parâmetros que, se forem admitidos pelos trabalhadores diretos enquanto ela é produzida, podem alterar positivamente a realização da mercadoria no mercado ${ }^{17}$. Ou seja, é por que o trabalhador/grupo de trabalho desta TRT tem o poder de interferir imediatamente na competitividade da empresa que ele precisa incorporar esta preocupação permanente com a melhoria constante e agir como se fosse um artesão.

Se, para Gramsci ${ }^{18}$, após o choque inicial das exigências musculares do método taylorista, teríamos o surgimento de uma "liberdade" mental dos operários que, durante o trabalho, poderiam pensar em assuntos mais nobres do que fazer com que alguém fique mais rico enquanto eu fico mais cansado, o modelo gerencial da TRT veta esta possibilidade. Trata-se portanto de uma intensificação da extração de mais valia além dos limites tradicionais do taylorismo. A minha pesquisa consistiu justamente no levantamento dos métodos pelos quais se produz este trabalhador que se pensa como artesão e que, por isso, confunde o incremento da produtividade com algo que ele imagina ser seu próprio bem estar.

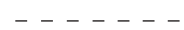

14 A idéia de melhoria constante é a base dos procedimentos da "gerência da qualidade total".

150 presidente da empresa que pesquisamos disse: "Eu quero uma empresa aonde as pessoas sejam felizes e se realizem ao máximo como pessoas. Eu quero que as pessoas tenham aquilo que 0 artesão tinha, ele comprava a matéria prima, ele fazia a peça, ele negociava no mercado e via os frutos do seu trabalho...ele tinha prazer na sua atividade, ele era a sua atividade". (grifos nossos).

16 Só o que não se deve esquecer é que, diferente do artesão, ele não é dono dos meios de produção nem da própria tecnologia e que a mercadoria que ajuda a produzir é destinada pela empresa ao mercado no qual ela pretende obter lucro com ela.

17 Este seria apenas uma das várias faces daquilo que se chamou de "acumulação flexível" (David Harvey, Condição Pós Moderna, São Paulo, Ed. Loyola, 1992).

18 Gramsci, op. cit, p.404.

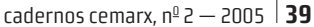

